\title{
CATAVENTO A GIRAR: ERRADICAÇÃO DO TRABALHO INFANTIL EM SUAS PIORES FORMAS
}

\author{
Maria Aurea Baroni Cecato* \\ Regina Coelli Batista de Moura Carvalho**
}

RESUMO: Este artigo aborda o trabalho infantil a partir, sobretudo, das Convenções 138 e 182 como parte do teor da Declaração de 1998 da OIT, no intuito de poder concluir se tais preceitos têm correspondência na realidade brasileira. Faz um paralelo com a figura do catavento, enquanto brinquedo que, por isso mesmo foi escolhido como símbolo da luta pela erradicação do trabalho infantil. O texto considera o trabalho decente como base dessa abordagem que é conceitual e teórico normativa, utilizando alguns dados estatísticos para confirmar os argumentos utilizados.

PALAVRAS-CHAVES: Trabalho decente. Trabalho infantil. Idade mínima. Piores formas. Erradicação.

\section{WEATHERVANE TO ROTATE: ERADICATION OF CHILD LABOR IN THE WORST FORMS}

\begin{abstract}
This article deals with child labor based, in particular, on Conventions 138 and 182 as part of the content of the ILO Declaration of 1998, in order to be able to conclude whether such precepts correspond in the brasilian reality. It parallels the figure of the weathervane, as a thoy that, for this reason, was chosen as a symbol of the struggle for the eradication of child labor. The text considers decent work as the basis of this approach, which is conceptual and normative, using some statistical data to confirm the arguments used.
\end{abstract}

KEYWOEDS: Decent work. Child labor. Minimum age. Worst forms. Eradication.

\footnotetext{
* Docente permanente do Programa de Pós-Graduação em Direito (PPGD-UNIPÊ) e docente colaboradora do Programa de Pós-Graduação em Ciências Jurídicas (PPDCJ-UFPB). Líder do Grupo de Pesquisa: Trabalho e desenvolvimento: influxos e dissensões (Plataforma CNPQ). Endereço eletrônico: mariaaurea.cecato@gmail.com.

** Graduada em Direito, Filosofia e História pela UFPI. Mestre em Filosofia e Teoria do Direito pela UFPE. Doutoranda em Direitos Humanos e Desenvolvimento pela UFPB. Juíza do Trabalho Substituta do Tribunal Regional do Trabalho da $22^{\mathrm{a}}$ Região. Professora do Curso de Direito da UFPI. Endereço eletrônico: reginacoellic@gmail.com.
} 


\section{INTRODUÇÃO}

O trabalho infantil é tema que suscita debates e ações no sentido de questionar as suas causas e buscar conscientização e meios para sua eliminação, especialmente em suas piores formas, como apresentado pela Organização Internacional do Trabalho (OIT).

Sabe-se que o trabalho infantil está intimamente ligado com a cultura, a pobreza e a miserabilidade social. Sabe-se, também, que sua efetiva abolição vincula-se à conscientização social e à educação. Não é demais lembrar que o surgimento do Direito do Trabalho teve como uma de suas razões a regulamentação do trabalho infantil, no sentido de limitação da jornada, com o intuito, assim, de proteger as crianças que trabalhavam como adultos desde o início da Revolução Industrial.

É conhecido como Revolução Industrial um conjunto de mudanças ocorridas inicialmente na Inglaterra e, posteriormente, estendendo-se pela Europa, caracterizado pelo desenvolvimento de máquinas, dentre elas a de algodão e a vapor, uso do tear mecânico, propiciando a substituição do trabalho artesanal pelo trabalho com máquinas e de forma assalariada. A introdução de máquinas permitiu a utilização da mão de obra de mulheres e crianças, trabalhadores mais dóceis e cuja remuneração era bem menor que a dos homens.

O trabalho infantil é uma das formas de trabalho não digno, ponto em que contraria a Constituição da República Federativa do Brasil. De igual forma, destoa de textos internacionais de grande importância. Assim, contrapõe-se ao trabalho decente, item primordial da Agenda da OIT ao longo de seus quase cem anos de existência (conquanto, por muito tempo, a expressão tal qual se apresenta hoje não tenha sido utilizada).

Nesse mesmo sentido, o trabalho infantil antagoniza-se, notadamente, com a Declaração sobre princípios e direitos fundamentais no trabalho, adotada pela OIT em 1998, documento que - a despeito de não abarcar materialmente o que se faz necessário para o labor realizado em condições de dignidade, tem grande relevância.

A importância da Declaração mencionada se prende, basicamente, à autoridade moral da Organização que a preceitua e abriga, mas também ao caráter cogente da mesma, obrigando todos os Estados Membros, a despeito de se tratar de uma Declaração. Com efeito, esses Estados, quando de sua filiação, concordam com os preceitos da Constituição da OIT, a qual, por sua vez, contem princípios correspondentes ao teor das oito Convenções que substancialmente formam a Declaração.

Dentre os princípios relativos aos direitos fundamentais, encontra-se a abolição efetiva 
do trabalho infantil, tendo a Declaração de 1998 da OIT associado, quanto a esse tema, as Convenções n. 138 e n. 182.

A Convenção n. 138 da OIT, de junho de 1973, seguida da Recomendação n. 146, trata, dentre outras questões, da idade mínima para o trabalho, vinculando essa idade à idade de conclusão da escolaridade compulsória ou, em qualquer caso, não inferior a quinze anos. Por sua vez, tratando das piores formas de trabalho infantil, em junho de 1999, foi concretizada a Convenção n. 182 da OIT, seguida da Recomendação da OIT n. 190, que cuida da implementação dos dispositivos da referida Convenção. Também a erradicação do trabalho infantil em suas piores formas faz parte dos objetivos estratégicos da OIT para alcance do direito humano ao trabalho decente.

O presente artigo tem como objetivo, abordar o trabalho infantil a partir, sobretudo, das Convenções 138 e 182, base da Declaração de 1998 da OIT sobre princípios e direitos fundamentais no trabalho, com o intuito de poder concluir se tais preceitos correspondem ou se aproximam da realidade brasileira.

Adota-se, como problema, o questionamento: a realidade brasileira corresponde ou aproxima-se dos preceitos das Convenções 138 e 182 da OIT, Convenções essas que formam parte da base da Declaração de 1998 da referida Organização? A abordagem do artigo é, como foi a pesquisa, conceitual e teórico normativa, mas adota dados estatísticos para consolidar argumentos.

\section{NOÇÃO DE TRABALHO INFANTIL}

A legislação brasileira entende por trabalho infantil toda e qualquer atividade realizada por criança, com idade inferior a 16 anos, cujo objetivo seja a obtenção de ganhos para a promoção de seu próprio sustento e/ou de sua família. Também é considerado trabalho infantil a atividade e o serviço que não são remunerados, como, por exemplo, trabalho voluntário ou forçado. Por exceção, se aceita o trabalho na condição de aprendiz, a partir dos 14 anos, e o trabalho infantil artístico, este autorizado no art. $8^{\circ}$ da Convenção n. 138 da OIT.

Considera-se, assim, trabalho infantil toda a forma de trabalho exercido por crianças abaixo da idade mínima legal permitida para o trabalho, conforme a legislação de cada país.

No Brasil, o Plano Nacional de Prevenção e Erradicação do Trabalho Infantil e Proteção ao Adolescente Trabalhador, define que: 
Trabalho infantil refere-se às atividades econômicas e/ou atividades de sobrevivência, com ou sem finalidade de lucro, remuneradas ou não, realizadas por crianças ou adolescentes em idade inferior a 16 (dezesseis) anos, ressalvada a condição de aprendiz a partir dos 14 (quatorze) anos, independentemente da sua condição ocupacional. Para efeitos de proteção ao adolescente trabalhador será considerado todo trabalho desempenhado por pessoa com idade entre 16 e 18 anos e, na condição de aprendiz, de 14 a 18 anos, conforme definido pela Emenda Constitucional $\mathrm{n}^{\circ} 20$, de 15 de dezembro de 1998 (BRASIL, 2011, p. 7).

A Constituição Federal de 1988 em seu art. $7^{\circ}$, inciso XXXIII trata da proibição de trabalho aos menores de 16 anos, salvo na condição de aprendiz, a partir de 14 anos (esse inciso foi alterado pela EC n. 20/1998, sob a influência da Convenção n. 138 da OIT e Recomendação n. 146 da OIT). O trabalho noturno, em atividades insalubres e perigosas, é vedado ao menor de 18 anos.

Quanto à especificação da faixa etária para enquadramento na condição de criança ou adolescente, não há uma unanimidade na legislação. O termo “criança”, empregado usualmente na atualidade, nem sempre foi adotado na nossa sociedade.

A CF/88 não especifica a faixa etária na qual enquadra a criança e o adolescente. Por sua vez, a Lei n. 8.069, de 13 de julho de 1990, que é o Estatuto da Criança e do Adolescente (ECA), utiliza as denominações criança e adolescente, considerando crianças as pessoas com idade até 12 anos incompletos e adolescentes as pessoas na faixa de idade entre 12 e 18 anos de idade.

O art. 402 da Consolidação das Leis do Trabalho (CLT) define menor como o "trabalhador de quatorze até dezoito anos", enquanto o art. 403 proíbe o trabalho de menores de 16 anos de idade, salvo na condição de aprendiz, a partir de 14 anos, em sintonia com a redação do art. $7^{\circ}$, inciso XXXIII, da CF/88.

A Convenção Internacional sobre os Direitos da Criança define, para os seus efeitos, criança como "todo ser humano com menos de dezoito anos de idade, a não ser que, em conformidade com a lei aplicável à criança, a maioridade seja alcançada antes” (art. $1^{\circ}$ ). Já para a Convenção n. 182 da OIT, que será estudada neste artigo, é considerada criança toda pessoa menor de 18 (dezoito) anos (art. $2^{\circ}$ ).

Como é cediço, grandes são os malefícios da inserção da criança no mercado de trabalho, configurando, o que denomina Palmeira Sobrinho (2010, p. 41-42) como uma 
“inclusão excludente", uma vez que o trabalho retira dessas crianças a sua sociabilidade, possibilidade de educação, dentre outros.

A importância da vedação do trabalho infantil reveste-se, assim, da necessidade de proteção da criança que ainda se encontra em fase de desenvolvimento, proteção essa que será analisada a seguir.

\section{PROTEÇÃO INTEGRAL À CRIANÇA: DESTAQUE PARA O TEXTO CONSTITUCIONAL E OS MAIS RELEVANTES DOCUMENTOS INTERNACIONAIS}

Em todas as fases da história humana, há registro de trabalho infantil, ganhando especial destaque a partir da Revolução Industrial, com o novo modelo de produção que se criou e com caráter de exploração.

O modelo de produção que era até então artesanal e caracterizado por ser realizado por homens, com a Revolução Industrial passou a produção a ser por máquinas e de forma assalariada. A introdução de máquinas na produção permitiu a utilização da mão de obra de mulheres e crianças, cujos custos eram bem mais baixos. Eram trabalhadores mais dóceis, com pouco conhecimento e cuja remuneração era bem menor que a dos homens, permitindo maior exploração. Esta era de tal monta que, nesse período, surgiram os movimentos sociais buscando, dentre outras, a regulamentação e limitação do trabalho das crianças.

O trabalho infantil está inserido em uma sociedade estruturada com desigualdade social e econômica e com mínimas, ou nenhuma, opções de escolha por parte das crianças menos favorecidas que ingressam precocemente no mundo do trabalho para sua sobrevivência ou ajudar no sustento da família. Há também a concepção inserida no imaginário social de que é preferível trabalhar a viver os perigos na rua.

Necessária, assim, a adoção de medidas pelo governo e pela sociedade no sentido de proteção das crianças, porquanto se trata da formação da personalidade da criança que será o adulto a participar das decisões na sociedade em que está inserido. $\mathrm{O}$ descaso na proteção e educação das crianças, sem a efetiva preocupação com sua essência e sua formação cívica, não prejudica somente as crianças, mas toda a sociedade.

É sabido que o trabalho precoce contribui para a evasão escolar, contribuindo, assim, para o pouco grau de instrução dessas crianças, sem maiores oportunidades, e a perpetuação da 
situação de miséria dos pais, num ciclo vicioso ${ }^{1}$.

Além do problema escolar, deve-se registrar o custo social do trabalho das crianças, tanto seja sob os aspectos físicos, psíquicos, emocionais e intelectuais da criança, quanto para a sociedade em razão da geração de mão de obra mais barata que acaba por depreciar o mercado de trabalho dos adultos, com o desemprego de quem tem a responsabilidade pelo sustento de seus filhos (ARRUDA, 2010, p. 38).

Nesse sentido, Brito Filho (2013, p. 113-114 e 124) reconhece o problema de utilização da mão de obra infantil por ser mais barata que a do adulto, privando a criança do seu desenvolvimento pleno, e afirma que o problema do trabalho infantil não está no ordenamento jurídico que é compatível com as normas internacionais, mas está prioritariamente nas práticas inconstitucionais e ilegais de utilização de crianças e adolescentes, devendo haver o máximo de rigor na repressão dessas práticas, aliadas com política social a manter crianças e adolescentes longe do trabalho que lhes é vedado.

A criança necessita de proteção para que tenha assegurado o seu crescimento saudável. Nocchi e Fava (2012, p. 14) registram que toda organização social, ordenada pela ideia do Estado busca assegurar a liberdade que, "para a criança, consiste no gozo da infância livre, envolta nas brincadeiras de formação, nos estudos fundamentais e na saúde do crescimento".

Várias são as normas internacionais que estabelecem proteção à criança. Piovesan e Luca (2010, p. 364) afirmam que um dos primeiros documentos internacionais a entender que as crianças devem "ser objeto de medidas de proteção foi a Declaração de Genebra dos Direitos da Criança, adotada pela Liga das Nações em 1924”. Essa Declaração não previa direitos, apenas invocava princípios a serem adotados pelos Estados para garantia do pleno desenvolvimento das crianças.

Em 1948, a Declaração Universal dos Direitos Humanos foi um dos primeiros diplomas a conceber a criança como sujeito de direitos, prevendo sua proteção social. Essa Declaração proclama um sistema de valor universal comum aos homens, de forma geral, e, por ser um processo resultado de lutas, conquistas, portanto, histórico, deve seu conteúdo continuamente ser atualizado, especificado, como é o caso da Declaração dos Direitos da Criança, que “apresenta o problema dos direitos da criança como uma especificação da solução dada ao

\footnotetext{
${ }^{1}$ A exemplificar, o ex-presidente do Conselho Brasileiro para a Infância e Adolescência, Antônio Carlos Gomes da Costa, afirmou que as crianças de famílias pobres estudam geralmente, um máximo de seis anos, com acentuado índice de repetência, e quase a metade das crianças que trabalham no Brasil (46,3\%) tem menos de 4 anos de instrução (Apud ARRUDA, 2010, p. 38).
} 
problema dos direitos do homem" (BOBBIO, 2004, p. 33-34).

A Declaração Universal dos Direitos da Criança, datada de 1959, afirma que a humanidade deve prestar à criança o melhor de seus esforços, enumerando direitos e liberdades a que faz jus toda criança. Referida Declaração estabelece no seu princípio $9^{\circ}$ que "A criança gozará de proteção contra quaisquer formas de negligência, crueldade e exploração [...]" e, no seu princípio $2^{\circ}$, prevê a proteção da criança como forma de garantir o seu pleno desenvolvimento em todos os aspectos, sendo garantido à criança o gozo de proteção especial, bem como "proporcionadas oportunidades e facilidades, por lei e por outros meios, a fim de lhe facultar o desenvolvimento físico, mental, moral, espiritual e social, de forma sadia e normal e em condições de liberdade e dignidade".

Há previsão de proteção aos direitos da criança também no Pacto Internacional de Direitos Civis e Políticos de $1966^{2}$ e no Pacto Internacional dos Direitos Econômicos, Sociais e Culturais de $1966^{3}$.

Por sua vez, a Convenção sobre os Direitos da Criança, adotada pela Assembleia Geral da ONU em 1989 e ratificada pelo Brasil, levou em conta que a necessidade de proporcionar à criança uma proteção especial já tinha sido enunciada em várias declarações anteriores, em pactos internacionais, os estatutos e instrumentos pertinentes das Agências Especializadas e das organizações internacionais que se interessavam pelo bem-estar da criança. Tal Convenção prevê, no seu art. 34, que o Estado deve proteger a criança contra a exploração sexual, especificamente contra a prostituição e a sua participação em qualquer produção de caráter pornográfico, atividades que são consideradas como piores formas de trabalho infantil.

Como já afirmado, a Convenção n. 138 da OIT estabelece dentre outras medidas, o limite de idade para o trabalho; e a Convenção n. 182 da OIT trata das piores formas de trabalho infantil e da urgência para sua eliminação.

No Brasil, a sociedade mobilizou-se para obter 200 mil assinaturas de adultos e mais de

\footnotetext{
${ }^{2}$ Art. 24.1 "Toda criança terá direito, sem discriminação alguma por motivo de cor, sexo, língua, religião, origem nacional ou social, situação econômica ou nascimento, às medidas de proteção que a sua condição de menor requer por parte de sua família, da sociedade e do Estado". Disponível em: < http://www.planalto.gov.br/ccivil_03/decreto/1990-1994/d0592.htm>. Acesso em: 02 mai. 2017.

${ }^{3}$ Art. 10.3 “3. Devem-se adotar medidas especiais de proteção e de assistência em prol de todas as crianças e adolescentes, sem distinção alguma por motivo de filiação ou qualquer outra condição. Devem-se proteger as crianças e adolescentes contra a exploração econômica e social. O emprego de crianças e adolescentes em trabalhos que lhes sejam nocivos à moral e à saúde ou que lhes façam correr perigo de vida, ou ainda que lhes venham a prejudicar o desenvolvimento norma, será punido por lei. Os Estados devem também estabelecer limites de idade sob os quais fique proibido e punido por lei o emprego assalariado da mão-de-obra infantil". Disponível em: <http://www.planalto.gov.br/ccivil_03/decreto/1990-1994/d0591.htm>. Acesso em: 02 mai. 2017.
} 
um milhão de assinaturas de adolescentes para apresentação da emenda popular que definiu o texto do art. 227 da Constituição Federal de 1988 e que bem sintetizou o princípio da proteção integral à infância no nosso país (COLUCCI, 2013, p. 57). O art. 227 da CF assegura, como proteção à criança e ao adolescente, com absoluta prioridade, o direito à vida, à saúde, à alimentação, à educação, ao lazer, à profissionalização, à cultura, à dignidade, ao respeito, à liberdade e à convivência familiar e comunitária, além de colocá-los a salvo de toda forma de negligência, discriminação, exploração, violência, crueldade e opressão. Esse dever de proteção é estabelecido em responsabilidade solidária da família, da sociedade e do Estado. Como parte do direito à proteção especial, conforme disciplinado no $\S 3^{\circ}$ do artigo constitucional em comento, estipula-se a idade mínima de quatorze anos para admissão ao trabalho, observado o disposto no art. $7^{\circ}, \mathrm{XXXIII}$, bem como a garantia de direitos previdenciários e trabalhistas; a garantia de acesso do trabalhador adolescente à escola, dentre outros. E de forma específica, há previsão de punição severa ao abuso, à violência e à exploração sexual da criança e do adolescente $\left(\S^{\circ}\right)$.

A Constituição Federal de 1988 adota, portanto, a proteção integral da criança e do adolescente e projetou um novo modelo jurídico que ditou as regras do Estatuto da Criança e do Adolescente - Lei n. 8.069/90 (COLUCCI, 2013, p. 58), cuja adoção do princípio da proteção integral está previsto nos seus arts. $1^{\circ}$ e $6^{\circ}$.

A proteção integral da criança e do adolescente tem, no Brasil, previsão legal, devendose, portanto, buscar sua efetivação. O Brasil é um país em desenvolvimento, mas que deve prezar pela proteção de seus cidadãos com direito ao desenvolvimento.

\section{DIREITO DO DESENVOLVIMENTO E DIREITO AO DESENVOLVIMENTO}

A abordagem do desenvolvimento, por razões diversas, é complexa. Uma dessas razões prende-se ao fato de ser, o termo "desenvolvimento", polissêmico e plural, além de, ainda, se fazer normalmente acompanhar de diferentes adjetivações, o que acaba lhe conferindo significados próprios. Dessa forma, a depender da adjetivação, ele pode ser entendido como desenvolvimento regional, desenvolvimento sustentável, além de outras denominações (FEITOSA, 2008).

Inicialmente, o termo desenvolvimento foi aplicado, em caráter científico, pelas ciências biológicas, sendo inserido posteriormente nas ciências sociais e humanas por meio da economia, com a característica de crescimento econômico (FRANCO, 2013, p. 141). Com o

Rev. de Direito do Trabalho e Meio Ambiente do Trabalho | e-ISSN: 2525-9857 | Maranhão | v. 3 | n. 2 | p. 21 - 41 | Jul/Dez. 2017 
tempo, transmudou-se o debate do desenvolvimento como crescimento econômico para a perspectiva dos direitos humanos (FEITOSA, 2013).

Sen (2010, p. 16) estuda o desenvolvimento como "um processo de expansão das liberdades reais que as pessoas desfrutam" e, portanto, como "um compromisso muito sério com as possibilidades de liberdade" (SEN, 2010, p. 378). Segundo Sen (2010), entender o desenvolvimento nesse sentido é voltar a atenção para as questões que tornam esse desenvolvimento relevante, tais como: pobreza e tirania, carência de oportunidades econômicas e destituição social sistemática, negligência dos serviços públicos e intolerância ou interferência excessiva de Estados repressivos.

O direito ao desenvolvimento foi incluído no catálogo dos direitos humanos fundamentais na década de oitenta (FEITOSA, 2008). A Assembleia Geral das Nações Unidas, através da Resolução n. 41/128, de 04 de dezembro de 1986, reconheceu o desenvolvimento como processo econômico, cultural, político e social a visar a melhoria do bem-estar da população e dos indivíduos com base na sua "participação ativa, livre e significativa no processo de desenvolvimento e na justa distribuição dos benefícios dele derivados”. Referida Resolução definiu no seu art. $1^{\circ}$, o direito ao desenvolvimento como direito humano inalienável em razão do qual todos os seres humanos e povos têm o direito de participar, de contribuir e de gozar o desenvolvimento econômico, social, cultural e político, no qual todos os direitos humanos e liberdades fundamentais se possam plenamente realizar (ONU, 1986).

Nessa perspectiva, Archer (apud FRANCO, 2013) relaciona três principais motivos para a maior proximidade entre direitos humanos e desenvolvimento, sendo eles: ascensão dos direitos humanos nas políticas internacionais, especialmente no pós-guerra; as políticas de desenvolvimento oficiais passaram a se concentrar mais diretamente nas causas da pobreza; e o reconhecimento, por parte dos ativistas de direitos humanos, da necessidade de se dedicarem também aos direitos sociais e econômicos.

Como ensina Feitosa (2013, p. 173-174), “o Direito do desenvolvimento se situa no âmbito do direito econômico constitucional, nas relações entre o Estado e os agentes de mercado, ainda que conjugados em prol do interesse social", relacionando-se com planos e programas setoriais, previsto em contexto normativo nacional, podendo ser encontrado no direito do trabalho, dentre outros. Por sua vez, o direito ao desenvolvimento "se situa no universo maior dos direitos humanos, caracterizado como direito de povos e coletividade, em privilégio da dimensão individual e social, nas relações que priorizam a dignidade humana" 
(FEITOSA, 2013, p. 173-174), relacionando-se com planejamento global e participação, às vezes, transnacional. Nessa perspectiva, seria exigida medida de reversão do quadro de desigualdade social, com melhorias do Índice de desenvolvimento humano ajustado à desigualdade (IDHAD) ${ }^{4}$, “em processo de inclusão social e participação comunitária, de organicidade diversa dos modelos adotados até o momento" (FEITOSA, 2013, p. 175).

Tratando sobre o tema Cecato (2012, p. 3) ensina que a Declaração da ONU estabelecendo o desenvolvimento como processo global, faz natural entender consequentemente que o direito que lhe é correspondente também seja dimensionado como amplo e abrangente. E continua afirmando que essa amplitude é inclusiva e abrange, sem distinção, "todos os trabalhadores, de todo espaço geográfico, de qualquer profissão, atividade, formação profissional, idade, cor, etnia e gênero" (CECATO, 2012, p. 3).

Direito do desenvolvimento e direito ao desenvolvimento quando bem conduzidos podem conviver harmoniosamente e alcançar bons resultados na instrumentalização das estruturas econômicas e sociais para efetivação de direitos, "em benefício do humano, na consolidação do chamado novo padrão civilizatório para a humanidade, que pondera a justiça ambiental com a sustentabilidade social” (FEITOSA, 2013, p. 175). Em outra perspectiva, mas que ilustra a questão do caráter global do direito ao desenvolvimento, Bobbio (2004, p. 44) defende que a "efetivação de uma maior proteção dos direitos do homem está ligada ao desenvolvimento global da civilização humana".

Trindade (2000, p. 100-101), após analisar o conteúdo da declaração da ONU sobre o direito ao desenvolvimento de 1986, distinguiu direito ao desenvolvimento, esse como um direito humano inalienável, do direito internacional do desenvolvimento, sustentando a tese da indivisibilidade dos direitos humanos e, assim, o direito ao desenvolvimento só pode reforçar direitos anteriormente formulados.

O direito ao desenvolvimento apresenta um novo discurso normativo, redefinindo o desenvolvimento para além da dimensão econômica, a fim de almejar a sua humanização e sua abrangência a todos os povos. Em tempo de crise, roga Franco (2013) para que os direitos humanos perseverem em sua construção de colocar o humano como ponto central do desenvolvimento. Tal proposição se encaminha no sentido do item 1 do art. $2^{\circ}$ da Resolução $n$.

\footnotetext{
${ }^{4} \mathrm{O}$ IDHAD computa as perdas ao nível do desenvolvimento humano impostas pela existência de desigualdades nacionais em cada uma das três dimensões do IDH. O IDH, ao apresentar médias, encobre desigualdades entre os indivíduos de um determinado Estado.
} 
41/128, da Assembleia Geral das Nações Unidas que coloca a pessoa humana como sujeito central do desenvolvimento.

A proteção integral da criança e do adolescente deve ser efetivada na perspectiva harmoniosa do direito do desenvolvimento com o direito ao desenvolvimento, especialmente, na eliminação do trabalho infantil em suas piores formas, condição necessária para a existência do trabalho decente.

A OIT defende o vínculo indissolúvel entre os temas econômicos e sociais, a garantir a integração das estratégias laborais, econômicas e financeiras que leve ao reconhecimento da política social como um fator produtivo (SOMAVÍA, 2014, p. 568) e coloca o trabalho decente - no quadro do qual se insere a proteção do trabalho infantil - como um imperativo do desenvolvimento, que será visto brevemente no próximo item.

\section{NOÇÃO DE TRABALHO DECENTE: RELEVÂNCIA DA ORGANIZAÇÃo INTERNACIONAL DO TRABALHO}

O trabalho possui significação social fundamental, pois vincula pessoas, famílias, comunidades e nação. Assim, a exclusão de pessoas do mundo do trabalho, seja por desemprego, por ausência de oportunidades ou outras causas, cria divisões sociais e, em muitos países sem a proteção adequada, ficam os trabalhadores e suas famílias entregues à própria sorte.

O Programa da OIT para 2000-2001 consistia basicamente em promover e aplicar os princípios e direitos fundamentais no trabalho; criar maiores oportunidades para trabalhadores a conseguir empregos decentes; melhorar a cobertura e eficácia da proteção social para todos e fortalecer o tripartismo e o diálogo social. Como critério orientador de todas as ações da OIT, optou-se pelo fomento do trabalho decente ${ }^{5}$ para se tornar global, já que esse trabalho sintetiza compromisso de direitos fundamentais no trabalho e proteção social (SOMAVÍA, 2014, p.564$565)$.

Para muitos homens, mulheres e famílias, a ausência do trabalho constitui "negação da

\footnotetext{
${ }^{5} \mathrm{O}$ conceito de "trabalho decente" aparece pela primeira vez na $87^{a}$ Conferência Internacional do Trabalho, no relatório apresentado pelo Diretor Geral da OIT, no qual afirma ser "O objetivo fundamental da OIT hoje é que cada mulher e cada homem possam ter acesso a um trabalho decente e produtivo em condições de liberdade, eqüidade, segurança e dignidade." A partir de então a noção de "trabalho decente" passa a ser discutida como base para a conceituação dos direitos humanos do trabalhador (CECATO, 2006, p. 10).
} 
participação do trabalhador em todas as dimensões do desenvolvimento" (CECATO, 2012, p. 6), eis que, sem trabalho, esse trabalhador perde o acesso ao ganho material, indispensável para sua sobrevivência, além de ter comprometida sua vida social, política e cultural.

E o que significa trabalho decente? "A abordagem do trabalho decente pode ser feita sob diversos prismas" (CECATO, 2012, p. 7), sendo aqui adotada a defendida pela OIT. Somavía (2014, p. 580) defende não ser uma noção intelectual, mas a forma de trabalho com liberdade, igualdade, segurança e dignidade humana. E esclarece que a definição do trabalho decente é dinâmica e muda à medida que uma sociedade avança suas formas sustentáveis de ganhar a vida e à medida que adquira mais recursos (SOMAVIA, 2014, p. 11 e 618). Começa pela eliminação da pobreza, mas não só. Não é só sobrevivência; é busca de vida plena, na qual o trabalhador possa canalizar todos os seus talentos e todas as suas energias (SOMAVÍA, 2014, p. 618).

Alvarenga (2012, p. 103) sustenta que "somente pela realização do direito fundamental ao trabalho decente", previsto no art. $6^{\circ}$ e outros da Constituição Federal, será preenchido o conteúdo da dignidade humana e da ordem econômica (art. $1^{\circ}$, III, e caput do art. 170, ambos da CF/88). Trabalho esse que tem função prospectiva, sinalizando aos sistemas socioeconômicos e jurídicos os caminhos que melhor realizam a dignidade humana; e no sentido de patamar mínimo de proteção laboral e de humanização do trabalho, donde não se poderá retroceder (FREITAS, 2013, p. 58).

Nesse sentido, tratando-se do trabalho decente, como forma de participação do trabalhador nas dimensões do desenvolvimento, deve-se entender que essas condições transbordam o ambiente laboral, eis que a dignidade do trabalhador se coloca "transversalmente nas condições de vida do trabalhador, posto que não existe nítida dissociação entre vida e trabalho" (CECATO, 2012, p. 18).

Dois aspectos devem ser observados em relação ao trabalho decente, quais sejam: positivo, consistente em que o trabalho decente é a expressão da dignidade humana no trabalho, com garantia da segurança e da saúde no meio ambiente laboral; e negativo, consistente no que o trabalho decente "só pode ser alcançado se antes for erradicado o trabalho escravo e infantil, se for eliminada a discriminação no emprego e assegurada a liberdade sindical" (AZEVEDO NETO, 2015, p. 61).

A OIT coloca o trabalho decente como o ponto de convergência de quatro pilares 
estratégicos, quais sejam: respeito aos direitos no trabalho ${ }^{6}$; a promoção do emprego produtivo e de qualidade; extensão da proteção social; e o fortalecimento do diálogo social (OIT, 2017). Na conjugação desses pilares, a luta pela erradicação do trabalho infantil insere-se na agenda do trabalho decente.

No Brasil, foi lançada, em maio de 2006, a Agenda Nacional de Trabalho Decente (ANTD), como resultado do Memorando de Entendimento, que previa o estabelecimento de um programa especial de cooperação técnica para a promoção de uma Agenda Nacional de Trabalho Decente no país, em consulta com as organizações de empregadores e de trabalhadores. Referida Agenda define três prioridades no país, quais sejam: a geração de mais e melhores empregos, com igualdade de oportunidades e de tratamento; a erradicação do trabalho escravo e eliminação do trabalho infantil, em especial em suas piores formas; e o fortalecimento dos atores tripartites e do diálogo social como um instrumento de governabilidade democrática.

Como se pode observar, a prioridade constante na ANTD, no Brasil, prevê a eliminação do trabalho infantil, estando em harmonia com as Convenções ns. 132 e 182 da OIT que serão a seguir analisadas.

\section{TRABALHO INFANTIL E TRABALHO DECENTE: APORTE DAS CONVENÇÕES 138 E 182 DA OIT}

Apesar dos esforços, muitas crianças ainda trabalham no mundo inteiro, inclusive, no Brasil.

A estimativa é de que 127 milhões de meninos e 88 milhões de meninas, ou seja, 215 milhões de crianças no mundo ainda estão envolvidas no trabalho infantil, sendo que, mais da metade desse número (74 milhões de meninos e 41 milhões de meninas) laboram nas piores formas de trabalho, à despeito de inúmeras normas internacionais e convenções da OIT que visam à proteção das crianças (OIT, 2012), além das normas internas dos Estados Membros.

No Brasil, dados da contínua Pesquisa por Amostra de Domicílios (PNAD), do Instituto Brasileiro de Geografia e Estatística (IBGE), demonstraram que o trabalho infantil aumentou

\footnotetext{
${ }^{6}$ Especialmente os definidos como fundamentais na Declaração de Direitos e Princípios Fundamentais no Trabalho de 1998, a saber: liberdade sindical e reconhecimento efetivo do direito de negociação coletiva; eliminação de todas as formas de trabalho forçado; abolição efetiva do trabalho infantil; e eliminação de todas as formas de discriminação em matéria de emprego e ocupação.
} 
4,5\% de 2013 para 2014, período em que 3,3 milhões de crianças e adolescentes de 5 a 17 anos estavam trabalhando no Brasil. Em 2015, encontrou-se 2,7 milhões de pessoas trabalhando, entre 5 a 17 anos, demonstrando uma diminuição do trabalho infantil no país (IBGE, 2015).

Com esses dados, conclui-se ainda ser necessária a disseminação da conscientização do combate ao trabalho infantil, especialmente em razão da urgência da erradicação de suas piores formas, como dever de toda a sociedade, do Estado e da família.

A Convenção n. 138 da $\mathrm{OIT}^{7}$, de junho de 1973, é instrumento que tem a intenção de substituir, gradualmente, as demais convenções que limitam a idade para o trabalho, em determinados setores econômicos, bem como efetivar a abolição do trabalho infantil, com a fixação de uma idade mínima permitida para o trabalho. Essa Convenção estabelece que todo país-membro que a ratificar deve especificar a idade mínima para admissão no emprego ou trabalho no seu território, que não será inferior à idade de conclusão da escolaridade compulsória ou em qualquer hipótese, não inferior a quinze anos. Contudo, permite a fixação do limite em quatorze anos aos países-membro, cuja economia e condições de ensino não estejam suficientemente desenvolvidas (CARVALHO, 2004, p. 69).

A Recomendação n. 146 da OIT, sobre a idade mínima de admissão ao emprego orienta a adoção de uma mesma idade mínima para todos os setores de uma atividade econômica, com o esforço de que a idade mínima para todos os países-membro seja elevada à idade de 16 anos, bem como recomenda a obrigatoriedade da frequência escolar integral, ou da participação em programas de orientação profissional e treinamento (OIT, 1973).

Por sua vez, a Convenção n. 182 da OIT $^{8}$, de junho de 1999, constitui instrumento complementar à Convenção sobre os Direitos da Criança da ONU, e trata das piores formas de trabalho infantil e da ação imediata para sua eliminação, determinando que todo Estadomembro que a ratificar deverá adotar medidas imediatas e eficazes que garantam a proibição e a eliminação das piores formas de trabalho infantil em caráter de urgência. Essa Convenção "representa o ápice do progressivo reconhecimento das especiais circunstâncias que circundam o mundo da criança e do adolescente de modo a impor sua proteção integral" (ARAÚJO JÚNIOR; MARANHÃO, 2010, p. 51).

A precarização e a força do elemento cultural são aspectos recorrentes do debate sobre

\footnotetext{
${ }^{7}$ Essa Convenção foi incorporada ao ordenamento jurídico brasileiro pelo Decreto n. 4.134, de 15.02.2002 e com vigência nacional em 28 de junho de 2002.

${ }^{8}$ Essa Convenção foi incorporada ao ordenamento jurídico brasileiro pelo Decreto n. 3.597, de 12.09.2000 e com vigência nacional em 02 de fevereiro de 2001.
} 
o trabalho infantil, mas a questão não é apenas cultural; é mais complexo na medida em que a exploração do trabalho infantil envolve em sua base questão econômica que "coloca em xeque o modo de produção capitalista", não sendo exagero defender-se que o trabalho infantil é "sintoma da degradação material e da desigualdade social que ressoa no modo de ser dos homens entre si” (PALMEIRA SOBRINHO, 2010, p. 39).

Nesse sentido, a Convenção n. 182 da OIT reconhece que o trabalho infantil é devido, em grande parte, “à pobreza e que a solução a longo prazo reside no crescimento econômico sustentado, que conduz ao progresso social, sobretudo ao alívio da pobreza e à educação universal" (OIT, 1999) e a urgência para sua eliminação, com ação global e imediata, que leve em consideração a importância da educação fundamental e da integração social.

A OIT, no relatório do seu Programa Internacional pela Erradicação do Trabalho Infantil (IPEC), Niños em Trabajo Peligrosos: Lo que sabemos lo que devemos hacer, apresenta os motivos da prioridade do enfrentamento do trabalho infantil em suas piores formas, quais sejam: a) magnitude do problema, uma vez que as estatísticas indicam o total de crianças em trabalhos perigosos é em torno de 115 milhões; b) o recente aumento do trabalho infantil perigoso entre os adolescentes: um incremento de $20 \%$ em quatro anos; c) a crescente evidência de que os adolescentes registram uma taxa de lesões no trabalho superior aos adultos; e d) concretas razões para acreditar se pode avançar mais rapidamente para a erradicação do trabalho infantil é em suas piores formas (OIT, 2011, p. XI).

Para os fins da Convenção n. 182 da OIT, a expressão "piores formas de trabalho infantil" compreende: a) todas as formas de escravidão ou práticas análogas à escravidão, como venda e tráfico de crianças, sujeição por dívida, servidão, trabalho forçado ou compulsório, inclusive recrutamento forçado ou obrigatório de crianças para serem utilizadas em conflitos armados; b) utilização, demanda e oferta de criança para fins de prostituição, produção de pornografia ou atuações pornográficas; c) utilização, recrutamento e oferta de criança para atividades ilícitas, particularmente para a produção e tráfico de entorpecentes conforme definidos nos tratados internacionais pertinentes; d) trabalhos que, por sua natureza ou pelas circunstâncias em que são executados, são suscetíveis de prejudicar a saúde, a segurança e a moral da criança.

A $18^{\text {a }}$ Conferência Internacional de Estatísticas do Trabalho da OIT, ocorrida em 2008, acolheu a Resolução II, com nova definição do trabalho infantil ao acrescentar novas hipóteses às previstas na Convenção 182 da OIT. Conforme a referida Resolução, não se observa apenas 
o aspecto econômico, passando "trabalho infantil" a referir-se: (I) às piores formas de trabalho infantil, incluindo trabalho escravo, prostituição e pornografia, atividades ilícitas e atividades que apresentam riscos à saúde, segurança ou integridade moral, conforme a Convenção n. 182 da OIT; (II) todas as atividades empregatícias realizadas por menores de 15 anos de idade, conforme a Convenção n. 138 da OIT; e (III) atividades domésticas, incluindo afazeres domésticos realizados por longo período de horas, em ambiente insalubre, em localizações perigosas, ou com uso de equipamentos perigosos ou pesados (PIOVESAN; LUCA, 2010, p. $363)$.

A Recomendação n. 190 da OIT trata sobre proibição das piores formas de trabalho infantil e ação imediata para sua eliminação, suplementando as disposições da Convenção n. 182 da OIT e recomendando ações a serem realizadas pelos Estados membros.

A regulamentação, no Brasil, dos arts. $3^{\circ}$, letra “d”, e $4^{\circ}$ da Convenção n. 182 da OIT ocorreu por meio do Decreto n. 6.481/2008 que criou a Lista das Piores Formas de Trabalho Infantil (Lista TIP). Em conformidade com a legislação brasileira, esse Decreto proíbe o trabalho em todas as suas atividades relacionadas na lista TIP para os menores de 18 anos, em sintonia com o disposto na Convenção n. 182 que determina a obrigação dos Estados definir, através de leis internas, os tipos de trabalho em suas piores formas, após consulta com as organizações de empregadores e de trabalhadores interessadas, levando em consideração, também, as normas internacionais pertinentes (especialmente os arts. $3^{\circ}$ e $4^{\circ}$ da Recomendação n. 190), além do exame periódico da relação dos tipos de trabalho, sempre, se necessário, em consulta com as organizações de empregadores e de trabalhadores interessadas.

Como se pode observar, a lista das piores formas de trabalho infantil, indicada pela OIT, é uma lista aberta que está sujeita a revisão, com inclusão de novas formas de trabalho, desde que elaborados pelas autoridades competentes e em consulta com as organizações de empregadores e de trabalhadores interessados, sempre atendendo à formação tripartida, marca da OIT.

Em 2006, quando o Brasil sediou a XVI Reunião Regional Americana da OIT, em Brasília, comprometeu-se a eliminar as piores formas de trabalho infantil até 2015 e a totalidade do trabalho infantil até 2020. 


\section{CONCLUSÃO}

Apesar da legislação, o trabalho infantil ainda é uma realidade, sendo, assim, necessário discutir suas causas, buscando conscientização e meios para sua erradicação, especialmente em suas piores formas.

O trabalho infantil é um problema complexo e está intimamente ligado com a cultura e a miserabilidade social e econômica, bem como sua abolição está diretamente vinculada à conscientização social e educação.

Vários instrumentos nacionais e internacionais preveem proteção à criança, destacandose neste artigo as Convenções da OIT de n. 138, que fixa o limite mínimo de idade para o trabalho e a de n. 182, que estabelece as piores formas de trabalho infantil, ambas ratificadas pelo Brasil e associadas à Declaração de Direitos e Princípios Fundamentais do Trabalho de 1998, da OIT. Defende-se que a erradicação do trabalho infantil e a proteção integral da criança devem ser efetivadas na perspectiva harmoniosa do direito do desenvolvimento com o direito ao desenvolvimento, um dos objetivos estratégicos para o trabalho decente.

Esse trabalho decente faz parte da agenda de desenvolvimento da OIT e tem como um dos seus quatro objetivos estratégicos, o respeito aos direitos no trabalho, especialmente os definidos como fundamentais na Declaração de Direitos e Princípios Fundamentais no Trabalho de 1998, dentre os quais consta abolição do trabalho infantil.

Em razão da imaturidade física e mental, a criança necessita de proteção e cuidados especiais. No Brasil, o art. $7^{\circ}$, inciso XXXIII, da Constituição Federal fixa a idade mínima para o trabalho em 16 anos, salvo na condição de aprendiz a partir dos 14 anos e o art. 227 da Constituição Federal de 1988 sintetiza o princípio da proteção integral à infância, pelo que se conclui que há legislação a ser aplicada de proteção à criança e vedação ao trabalho infantil, necessitando-se apenas buscar a sua efetivação.

Neste artigo, conclui-se também que a legislação brasileira teoricamente é avançada e alinha-se aos preceitos das Convenções n. 138 e n. 182 da OIT, mas a realidade já não tem a mesma sintonia. Após mais de dez anos da vigência no nosso país das Convenções ns. 138 e 182 da OIT, a realidade brasileira encaminha-se, mesmo que de forma lenta, para alinhar-se aos preceitos dessas Convenções diante da diminuição do trabalho infantil como demonstram as estatísticas de 2014 para 2015, com redução de 3,3 milhões para 2,7 milhões de trabalhadores na idade entre 5 a 17 anos, portanto, foram afastadas mais 600 mil crianças do trabalho no Brasil, o que corresponde a um percentual aproximado de 19,5\%, conforme dados do IBGE. 
Dados obtidos no Ministério da Saúde do nosso país, em seu Sistema de Informação de Agravos de Notificação (SINAN), demonstram que os acidentes de trabalho grave, em crianças de 5 a 17 anos, notificados no Sistema Único de Saúde (SUS), aumentaram de 3.517 em 2012 para 3.716 notificações em 2013. Contudo, a partir de 2014 essas notificações de acidente de trabalho grave passaram a diminuir, com registro de 3.437 nesse ano, 2.883 notificações em 2015 e 1924, em 2016. Certo que essas notificações não representam todos os acidentes de trabalho grave ocorridos em trabalhadores de 5 a 17 anos, pois muitos não são notificados, mas servem de indício a demonstrar que o Brasil não cumpriu seu compromisso com a OIT porque não erradicou em 2015 o trabalho infantil em suas piores formas e, talvez, pela evolução, não erradicará todo trabalho infantil até 2020. Conclui-se, por fim, que essa redução do trabalho infantil não é suficiente, não havendo ainda uma correspondência ou alinhamento da realidade brasileira com os preceitos das Convenções 138 e 182 da OIT, sendo mister intensificar as ações para a completa erradicação do trabalho infantil, especialmente em suas piores formas.

O símbolo do dia mundial de combate ao trabalho infantil, criado no Brasil e adotado pela OIT para todo o mundo, é um catavento, um brinquedo infantil. O catavento caracteriza movimento e produção de energia; é colorido, constituído de cinco pontas que, simbolicamente, representam os cinco continentes e a diversidade de gênero e raça. Colorido como deve ser o universo infantil e instrumento que representa mudança e transformação.

O combate ao trabalho infantil, especialmente em suas piores formas, deve ser um compromisso solidário da sociedade, do Estado e da família para que o catavento possa girar alegremente e voltar a ser um simples brinquedo de criança.

\section{REFERÊNCIAS}

ALVARENGA, Rúbia Zanotelli de. O trabalho decente como direito humano e fundamental. Revista Fórum Trabalhista, ano 1, n. 1, mar./abr. 2012, Belo Horizonte: Fórum, 2012. p. 85104.

ARAÚJO JÚNIOR, Francisco Milton; MARANHÃO, Ney Stany Morais. Considerações sobre o combate à exploração do trabalho infantil: bosquejo histórico, proteção jurídica e realidade humana. In: NOCCHI, Andrea Saint Pastous; VELLOSO, Gabriel Napoleão; FAVA, Marcos Neves (Org.). Criança, adolescente, trabalho. São Paulo: LTr, 2010. p. 45-71.

ARRUDA, Kátia Magalhães. As piores formas de trabalho e o direito fundamental à infância. In: SENA, Adriana Goulart; DELGADO, Gabriela Neves; NUNES, Raquel Portugal (coord.). Dignidade Humana e inclusão social: os caminhos para a efetividade do Direito do Trabalho no Brasil. São Paulo: LTr, 2010, p. 34-44. 
AZEVEDO NETO, Platon Teixeira de. O trabalho decente como um direito humano. São Paulo: LTr, 2015.

BOBBIO, Norberto. A era dos direitos. Trad. Carlos Nelson Coutinho. Rio de Janeiro: Elsevier. 2004.

BRASIL. Instituto Brasileiro de Geografia e Estatística - IBGE. Disponível em:<ftp://ftp.ibge.gov.br/Trabalho_e_Rendimento/Pesquisa_Nacional_por_Amostra_de_Dom icilios_anual/2006/Suplementos/trab_infantil. Acesso em: 04 mai. 2017.

Plano Nacional de Prevenção e Erradicação do Trabalho Infantil e Proteção do Adolescente Trabalhador. Comissão Nacional de Erradicação do Trabalho Infantil. 2. ed. Brasília: Ministério do Trabalho e Emprego, 2011.

BRITO FILHO, José Cláudio Monteiro de. Trabalho decente: análise jurídica da exploração do trabalho - trabalho escravo e outras formas de trabalho indigno. 3. ed., São Paulo: LTr, 2013.

CARVALHO, Regina Coelli Batista de Moura. Idade e trabalho: abordagem sociojurídica sobre a limitação da idade para o trabalho no Brasil. Porto Alegre: Sérgio Antônio Fabris, 2004.

CECATO, Maria Aurea Baroni. Interfaces do trabalho com o desenvolvimento: inclusão do trabalhador segundo os preceitos da declaração de 1986 da ONU. Prima Facie. João pessoa, v. 11, n. 20, ano 11, jan-jun., 2012, p. 23-42. Disponível em:

<file:///C:/Users/JUIZ/Downloads/13805-24643-1-PB\%20(1).pdf>. Acesso em: 02 mai. 2017.

A relativa relevância da Declaração de 1998 da OIT para a definição dos direitos humanos do trabalhador. Prima Facie. João pessoa, v. 5, n. 8, jan-jun. 2006. Disponível em: Disponível em: <periodicos.ufpb.br/index.php/primafacie/article/download/6783/4218. Acesso em: 30 jun. 2017.

COLUCCI, Viviane. A teoria da proteção integral frente ao combate ao trabalho infantil e à regularização do trabalho do adolescente. Revista do Tribunal Superior do Trabalho, ano 79, n. 1, jan. a mar. 2013, Rio de Janeiro: Imprensa Nacional, 2013, p. 55-65.

FEITOSA, Maria Luiza Alencar M. Desenvolvimento econômico e direitos humanos. Coimbra: Gráfica de Coimbra - Boletim de Ciências Econômicas LII, 2008.

. Direito Econômico do Desenvolvimento e Direito humano ao desenvolvimento. Limites e Confrontações. In: FEITOSA, Maria Luiza Alencar Mayer et al. Direitos humanos de solidariedade: avanços e impasses. Curitiba: Appris, 2013. p. 171-240.

FRANCO, Fernanda Cristina Oliveira. O direito ao desenvolvimento como resultado do encontro entre direitos humanos e desenvolvimento. In: FEITOSA, Maria Luiza Alencar Mayer et al. Direitos humanos de solidariedade: avanços e impasses. Curitiba: Appris, 2013. p. 139-170.

FREITAS, Carolina. A defesa do trabalho decente e a substituição processual em Portugal 
e no Brasil. São Paulo: LTr, 2013.

NOCCHI, Andréa Saint Pastous; FAVA, Marcos Neves. Enfrentamento do trabalho infantil Mais que uma escolha, uma obrigação. Revista Fórum Trabalhista: RFT, ano 2, n. 08, p. 14, Belo Horizonte, Fórum, 2012.

ORGANIZAÇÃO DAS NAÇÕES UNIDAS (ONU, 1986). Declaração sobre o direito ao desenvolvimento. Disponível em:<http://direitoshumanos.gddc.pt/3_16/IIIPAG3_16_5.htm>. Acesso em: 06 mar. 2017.

(ONU, 1989). Convenção Internacional sobre os direitos da criança. Disponível em: < http://www.planalto.gov.br/ccivil_03/decreto/1990-1994/d99710.htm>. Acesso em: 10 mai. 2017.

. (ONU, 1948). Declaração universal dos direitos humanos. Disponível em:

<http://www.direitoshumanos.usp.br/index.php/Declara\%C3\%A7\%C3\%A3o-Universal-dosDireitos-Humanos/declaracao-universal-dos-direitos-humanos.html>. Acesso em: 08 mai. 2017.

ORGANIZAÇÃO INTERNACIONAL DO TRABALHO (OIT, 2017). O que é o trabalho decente. Disponível em: < http://www.oitbrasil.org.br/content/o-que-e-trabalho-decente>. Acesso em: 06 jun. 2017.

. (OIT, 1973). Convenção n. 138. Disponível em: <www.oitbrasil.org.br/node/492>. Acesso em: 06 jun. 2017.

. (OIT, 1999). Convenção n. 182. Disponível em: <www.oitbrasil.org.br/node/518>. Acesso em: 06 jun. 2017.

(OIT, 1973). Recomendação n. 146. Disponível em:

<www.oit.org.br/sites/all/ipec/normas/rec146.php>. Acesso em: 06 jun. 2017.

(OIT, 1999). Recomendação n. 190. Disponível em:

<www.oitbrasil.org.br/content/sobre-proibição-das-piores-formas-de-trabalho-infantil-e-açãoimediata-para-sua-eliminação>. Acesso em: 06 jun. 2017.

(OIT, 2011). Niños en trabajos peligrosos: Lo que sabemos, lo que debemos

hacer. Programa Internacional para la erradicación del trabajo infantil (IPEC). Ginebra, 2011.

PALMEIRA SOBRINHO, Zéu. O trabalho infantil: um balanço em transição. In: NOCCHI, Andréa Saint Pastous; VELLOSO, Gabriel Napoleão; FAVA, Marcos Neves (Org.). Criança, Adolescente, Trabalho. São Paulo, LTr: 2010.

PIOVESAN, Flávia; LUCA, Gabriela de. Gênese e atualidade da proteção ao trabalho infantil nas normas internacionais: trabalho infantil como violação aos direitos humanos. In:

NOCCHI, Andrea Saint Pastous; VELLOSO, Gabriel Napoleão; FAVA, Marcos Neves (org.). Criança, Adolescente, Trabalho. São Paulo: LTr, 2010. 
SEN, Amartya. Desenvolvimento como liberdade. Trad. Laura Teixeira Motta. Rev. Tec. Ricardo Doninelli Mendes. São Paulo: Companhia das Letras, 2010.

SOMAVÍA, Juan. El trabajo decente: un imperativo del desarrollo. In: El trabajo decente: uma lucha por la dignidade humana. Santiago: Organización Internacional del Trabajo, 2014. p.561-620.

TRINDADE, Antônio Augusto Cançado. A proteção internacional dos direitos humanos e o Brasil. 2. ed. Brasília: Universidade de Brasília, 2000. Série Prometeu. Edições Humanidades. 